\begin{abstract}
"This is the pre-peer reviewed version of the following article: Nathalie Pytlik, Benjamin Klemmed, Susanne Machill, Alexander Eychmüller, Eike Brunner (2019). In vivo uptake of gold nanoparticles by the diatom Stephanopyxis turris. Algal Research, Volume 39, pp. 101447, which has been published in final form at DOI:10.1016/j.algal.2019.101447.
\end{abstract}

\title{
In vivo uptake of gold nanoparticles by the diatom Stephanopyxis turris
}

\author{
Nathalie Pytlik ${ }^{\mathrm{a}}$, Benjamin Klemmed ${ }^{\mathrm{b}}$, Susanne Machilla, Alexander Eychmüllerb, Eike Brunner ${ }^{\mathrm{a}}$ \\ a Chair of Bioanalytical Chemistry, TU Dresden, Bergstraße 66, 01069 Dresden, Germany \\ b Chair of Physical Chemistry, TU Dresden, Bergstraße 66b, 01062 Dresden, Germany
}

\section{Abstract}

Nanoparticle (NP) implementation in industry has increased during the last years. However, the consequences of NP release to the environment have not been fully understood yet and long-term effects are hardly predictable. Information regarding a possible NP uptake by organisms is urgently needed. Here, we investigate the uptake of presynthesized AuNPs of different diameters by living diatoms. To better understand the influence of NPs on diatoms, cells were monitored in vivo using Surface Enhanced Raman Spectroscopy (SERS). By 3D Raman imaging, AuNPs with diameters $\geq 50 \mathrm{~nm}$ could clearly be localized inside the cells, whereas smaller AuNPs were never detected in the cell interior. This indicates a sizedependent uptake mechanism that comes along with different toxicities. As diatoms present an essential source of the marine food chain, this observation is relevant not only for diatoms themselves but also for higher organisms.

\section{Introduction}

NPs have gained enormous scientific interest [1-3]. Meanwhile, they are also increasingly produced by industry with an approximate amount of 10.000 tons per year (state 2012) [4]. However, their rising distribution and accumulation in the biosphere may cause environmental problems [5]. It is, therefore, necessary to study the uptake of NPs by organisms, for example diatoms. These unicellular organisms belong to the group of microalgae. More than $10^{5}$ different species are found in both freshwater and marine environments [6]. Although only visible by microscope, these tiny organisms are crucial for the existence of life. They are responsible for about $20 \%$ of the global oxygen production by photosynthesis [7]. To date, the knowledge about toxic interactions or possible NP uptake mechanisms by diatoms is very limited. Most hypotheses about cell wall or membrane penetration of NPs rely on studies of other organisms $[5,8,9]$. To evaluate the ecotoxicological impact of NPs upon diatoms, intensive studies regarding the $\mathrm{NP}$-diatom interaction and possible NP uptake mechanisms are necessary. Having in mind the importance of diatoms for photosynthesis [10] and as essential part in the food chain of the ocean [11], investigation of the impact of AuNPs on diatoms is of high biological and ecological interest.

Diatoms are also a promising research object in bio-nanotechnology $[12,13]$ with respect to bio-inspired approaches for new syntheses of semiconductor, photonic, and drug delivery nanomaterials $[7,14]$. Apart from the functionalization of their cell walls, diatoms have currently been studied as potential biosynthesizers of metal NPs [15-

20]. Understanding the biochemical mechanisms underlying NP biosynthesis is essential for the improvement of NP homogeneity and, thus, for the application of this environment-friendly synthesis method in the future [21]. Elucidation of the NP-diatom interaction mechanisms can, thus, not only help to estimate the effect of AuNPs on our environment but also to improve the properties of biosynthesized NPs.

To obtain in vivo information about algae, SERS (Surface Enhanced Raman Spectroscopy) has been proven to be a valuable tool [22]. We have recently used SERS to determine NP localization in living diatom cells. In vivo biosynthesized AuNPs from the addition of gold salt to the growth medium were detected inside the diatom cells [19]. The condition for the observation of SERS spectra is a close contact between the sample and metallic nanostructures. This proximity leads to enhanced

Raman intensities of sample molecules [23]. It is, however, not yet clear, whether the intracellular AuNPs are formed a) intracellularly from reduced gold ions which could enter the cell via ion channels or simple diffusion or b) outside the diatom cell using cell-wall-attached substances or reducing agents from the growth medium and transported into the diatom cell afterwards by diffusion or endocytosis. Possible

mechanisms for NP uptake have recently been summarized [9]. Experimental evidence for NP uptake by diatom cells has so far been provided by transmission electron microscopy [24], spectrophotometry

[25], focused ion beam [26], and atomic force microscopy [27]. However, all these analytical methods either require chemically fixed, dead diatom cells or can only reveal information regarding NPs outside 
the diatom cell wall. In vivo monitoring of NP-diatom interactions is necessary in order to ultimately show the uptake of NPs by living cells. If living cells are able to take up NPs, both ways ( $a$ and b) to biosynthesize intracellular AuNPs are possible, and if AuNPs cannot be taken up, option b is not likely to occur. In this work, we have analyzed Stephanopyxis turris (S. turris) cells in vivo after exposure to presynthesized AuNPs of various diameters. The main question investigated is the uptake and localization of AuNPs as well as their effect on cell vitality.

\section{Materials and methods}

\subsection{Cultivation}

S. turris was isolated by Prof. M. Sumper (Regensburg) from the North Sea in June 2004 and recently molecularly characterized [19]. Following the protocol of the North East Pacific Collection from Harrison et al. [28], cells were kept in artificial seawater medium (ASW). Cultivation was performed in a RUMED 1301 light thermostat $\left(18{ }^{\circ} \mathrm{C}\right.$, 12/12 h day/night cycle and about $1000 \mathrm{~lx}$ ).

\subsection{AuNP synthesis}

The following materials were used as purchased: hydrogen tetrachloroaurate trihydrate $\left(\mathrm{HAuCl}_{4} 3 \mathrm{H}_{2} \mathrm{O}, \geq 99.9 \%\right.$, Alfa Aesar), L-ascorbic acid ( $\geq 99 \%$, Alfa Aesar), trisodium citrate dihydrate ( $\geq 99 \%$, SigmaAldrich) and ultrapure water (Milli-Q, $>18.25 \mathrm{M} \Omega$ ). The seed solution was prepared using a citrate reduction method according to Frens [29]. First, $125 \mu \mathrm{L}$ of a $0.1 \mathrm{MHAuCl}_{4} \cdot 3 \mathrm{H}_{2} \mathrm{O}$ stock solution was added to $50 \mathrm{~mL}$ of water and heated up to boiling temperature. Subsequently, $2 \mathrm{~mL}$ of an aqueous trisodium citrate dihydrate stock solution $(1 \% \mathrm{w} / \mathrm{v})$ were added quickly under vigorous stirring. The solution was kept boiling for $5 \mathrm{~min}$ and was then allowed to cool down.

AuNPs with different diameters were grown following the former published protocol of Ziegler and Eychmüller [30]. A defined amount of the afore synthesized seed solution was diluted in $20 \mathrm{~mL}$ water. Apart from that, a precursor solution (a) was prepared by diluting a $5 \mathrm{mM}$ $\mathrm{HAuCl}_{4} \cdot 3 \mathrm{H}_{2} \mathrm{O}$ stock solution to $10 \mathrm{~mL}$. For the reducing solution (b) a mixture of ascorbic acid stock solution (b1) $(1 \% \mathrm{w} / \mathrm{v})$ and trisodium citrate stock solution (b2) $(1 \% \mathrm{w} / \mathrm{v})$ were diluted to $10 \mathrm{~mL}$. The relative volume ratio of all three stock solutions a:b1:b2 was always kept at $8: 2: 1$. Subsequently, $10 \mathrm{~mL}$ precursor solution (a) and $10 \mathrm{~mL}$ reducing solution (b) were added to the seed solution under stirring using separate Teflon tubes and a peristaltic pump. This process took place at room temperature for $45 \mathrm{~min}$. After the complete addition of both solutions ( $\mathrm{a}$ and $\mathrm{b}$ ) the mixture was heated up to boiling temperature and kept there for $30 \mathrm{~min}$. Finally, the solution containing the grown AuNPs was allowed to cool down. The required amount of gold precursor to achieve the different, desired AuNP diameters was calculated taking into account the seed-particle diameter and concentration. Furthermore, a complete turnover of the gold precursor without additional seed formation was assumed.

Grown AuNPs were characterized using transmission electron microscopy (TEM). Concentration of the AuNP solutions was determined using ultraviolet/visible spectroscopy (UV/Vis) according to Haiss et al. [31].

\subsection{Exposure to $A u N P s$}

AuNPs of different diameters were separately added to $S$. turris cells in ASW for $24 \mathrm{~h}$ reaching a final NP concentration of $10^{-12} \mathrm{M}$. To find the optimum NP concentration, for each AuNP diameter three different AuNP concentrations $\left(10^{-16} \mathrm{M}, 10^{-14} \mathrm{M}, 10^{-12} \mathrm{M}\right)$ were added to living diatom cells. At least 10 of these cells were analyzed in 2D Raman images and the probability to obtain at least one SERS spectrum in each of the $2 \mathrm{D}$ images was compared. The concentration $10^{-12} \mathrm{M}$ was evaluated as the best concentration to receive a reproducible and high possibility to generate SERS spectra for each measured cell.

\subsection{Toxicity test}

For toxicity tests, diatom cells in ASW were incubated with $10^{-16}$, $10^{-14}$ or $10^{-12} \mathrm{M}$ AuNP solution for the 5 synthesized AuNP diameters. Cells were analyzed at these three concentrations $4 \mathrm{~h}, 1 \mathrm{~d}, 2 \mathrm{~d}, 3 \mathrm{~d}, 4 \mathrm{~d}$, and $7 \mathrm{~d}$ after adding the AuNPs. Monitoring during toxicity tests was performed using a Keyence BZ-8000 K microscope with an ELWD objective Plan Fluor 20x from Nikon $\left(\mathrm{N}_{\mathrm{A}}=0.45\right)$. Images were acquired with 10-fold magnification. For fluorescence investigations cells were tested using an OP-66834 BZ DAPI-BP filter set and an acquisition time of $0.5 \mathrm{~s}$.

\subsection{Transmission electron microscopy (TEM)}

$5 \mu \mathrm{L}$ sample solution were dried on 200 mesh Cu TEM grids with formvar/coal-films from Plano. In case of ASW and diatom cells containing samples the solution was dialysed before drying and centrifuged for $5 \mathrm{~min}$ at $5000 \mathrm{rpm}$ using an Eppendorf $5417 \mathrm{R}$ centrifuge. Dialyses was performed for desalination overnight in a ZelluTrans membrane (MWCO 4000-6000 from Roth) against 2 L ultrapure water. Samples were measured at a JEM 1400plus $(120 \mathrm{kV})$ equipped with a $\mathrm{LaB}_{6}$ cathode. The program Image $1.48 v$ by $W$. Rasband enabled the determination of the AuNP diameters from the TEM images. After synthesis $100 \mathrm{NPs}$, and after incubation in diatom cell solution 30 AuNPs were considered for the calculations.

\subsection{Raman investigations}

Samples were investigated after immobilization on Poly-L-Lysin [32] coated $\mathrm{CaF}_{2}$ slides using a $60 \times\left(\mathrm{N}_{\mathrm{A}}=1.00\right)$ water immersion objective from Nikon. Following former results [19] regarding cell viability, the laser power of $8 \mathrm{~mW}$ was combined with an exposition time of $109 \mathrm{~ms}$ as "soft" conditions for imaging. 2D images were recorded at $1 \mu \mathrm{m}$ step size distances in $x-y$ - and 3D images additionally at $3 \mu \mathrm{m}$ distance in $\mathrm{z}$ direction. Recording the 3D images usually acquired about $80 \pm 20 \mathrm{~min}$ per cell. For each AuNP diameter, at least 3 diatom cells have been imaged in $3 \mathrm{D}$, and 10 cells respectively in $2 \mathrm{D}$. The single pigment spectrum (Fig. 3, top) was measured using a laser power of $95 \mathrm{~mW}$ and an exposure time of $5 \mathrm{~s}$. All measurements were carried out using a Raman spectrometer HoloLab Series 5000 from Kaiser Optical Systems [33] containing a $20 \mu \mathrm{m}$ fiber-coupled single-mode laser at a wavelength of $785 \mathrm{~nm}$. A back-illuminated CCD detector (Roper Scientific, USA) with deep-depletion design was employed. Evaluation of the collected Raman spectra was realized using the in-house developed software Spectrallmaging by $M$. Finger. The strongest bands of $\beta$-carotene and fucoxanthin were plotted according to their spectral intensities and used to represent the cell chloroplast in the 3D false color images. Presented Raman spectra are baseline corrected.

\section{Results and discussion}

\subsection{Scope of the experiment}

The silica cell wall of $S$. turris exhibits a highly regular pore pattern (cribrum) with pore diameters of about 50-200 nm (see Supporting information, Fig. S1), which forms the bottom of hexagonal chambers (areolae) with about $2.3 \mu \mathrm{m}$ diameter [34]. Native diatom cell walls are surrounded by an organic layer. Furthermore, another organic layer rich in polysaccharides (diatotepum) is located between the cell wall and the cell membrane. The latter is directly adjacent to the cell wall $[35,36]$. AFM investigations of $S$. turris cells suggest that the diatotepum of this species is only localized at the inner surface of the cribrum [35]. This matrix contains polysaccharides and proteins (mainly 
in $\beta$-strand and random-coil conformation; dominated by five amino acids) that together shield the silica structure [37]. It is well known, that diatoms take up inorganic nutrients (e. g. iron, phosphate, or ammonium). These nutrients are transported through the pores of the siliceous cell wall and finally through the cell membrane in dissolved ionic form. It is believed that ions including potassium, nitrate, ammonium, sodium, and calcium cross the membrane through channels via action potentials [36]. Iron uptake is possible in the form of ionic Fe (III) or Fe(II) after reduction of iron bound by siderophores [38]. However, it was recently reported that the diatom species Phaeodactylum tricornutum can also take up hydroxamate siderophores without previous reduction following an alternative endocytosis pathway [39].

Earlier ecotoxicological studies with respect to the impact of $\mathrm{TiO}_{2}$ NPs upon diatoms have suggested a size-dependent influence $[40,41]$. Therefore, we have used AuNPs of different diameters, namely $19 \mathrm{~nm}$, $31 \mathrm{~nm}, 51 \mathrm{~nm}, 75 \mathrm{~nm}$, and $125 \mathrm{~nm}$. These AuNPs were synthesized, characterized, and added to living $S$. turris cells in artificial sea water (ASW). The cells were studied in vivo using 3D SERS to localize the AuNPs.

\subsection{TEM characterization of AuNPs}

AuNPs of different sizes were characterized directly after synthesis and after $24 \mathrm{~h}$ incubation in ASW with $S$. turris cells. Comparison of the TEM images shows nearly no changes of NP shape (see Fig. 1) and size (see Fig. 2). Fig. 1 compares TEM images of the AuNPs directly after synthesis and after incubation in ASW with diatom cells. AuNP diameters after synthesis were analyzed as $19 \pm 7 \mathrm{~nm}, 31 \pm 3 \mathrm{~nm}$, $51 \pm 6 \mathrm{~nm}, 75 \pm 9 \mathrm{~nm}$, and $125 \pm 15 \mathrm{~nm}$. Figs. 1 and 2 show that incubation in ASW with diatom cells neither changed the AuNP diameters nor their shapes significantly. After incubation in diatom containing solution, fine structures were observable additionally to the AuNPs (see Fig. 1, right column). As similar results were obtained after incubation in ASW without diatoms (data not shown), it is likely that these low-contrast structures contain ASW constituents like $\mathrm{Na} 2$ EDTA $2 \mathrm{H}_{2} \mathrm{O}$, thiamine, vitamin $\mathrm{B} 12$, or biotin.

Sample preparation does not allow conclusions regarding intracellular AuNPs as it is not clear whether or not the observed AuNPs originate from the cell surrounding cultivation medium, the cell wall, or the cell interior. It can, thus, not be excluded that intracellular AuNPs are not depicted in these TEM images and behave differently. It is, nevertheless, remarkable that the observed AuNPs have not changed in terms of size and shape in the presence of diatom cells and cultivation medium.

\subsection{Cell viability}

Using the optimum AuNP concentration of $10^{-12} \mathrm{M}$ during the chosen incubation time of one day, fluorescence of chlorophyll $a$ (as an indicator for cell vitality) was only affected by the biggest AuNPs of $125 \mathrm{~nm}$ diameter. Light microscopic images confirm the integrity of the diatom cell wall even for the $125 \mathrm{~nm}$ AuNPs (see Supporting information, Figs. S2 and S3).

\subsection{Spectroscopic investigations}

\subsubsection{Raman spectroscopy}

The Raman spectrum of bare S. turris cells without AuNPs was measured with $95 \mathrm{~mW}$ laser power and an exposure time of $5 \mathrm{~s}$. This resonance-enhanced Raman spectrum is dominated by pigmentswhich are located inside the diatom chloroplast. The most intense bands of this spectrum are known to originate from chlorophyll $a$, fucoxanthin, and $\beta$-carotene (see Fig. 3, top) [19]. Since the chloroplast practically covers the entire volume of living diatom cells, this pigment-dominated spectrum can be used to detect the cell shape also by Raman imaging
After synthesis

\section{After incubation in ASW with diatom cells}
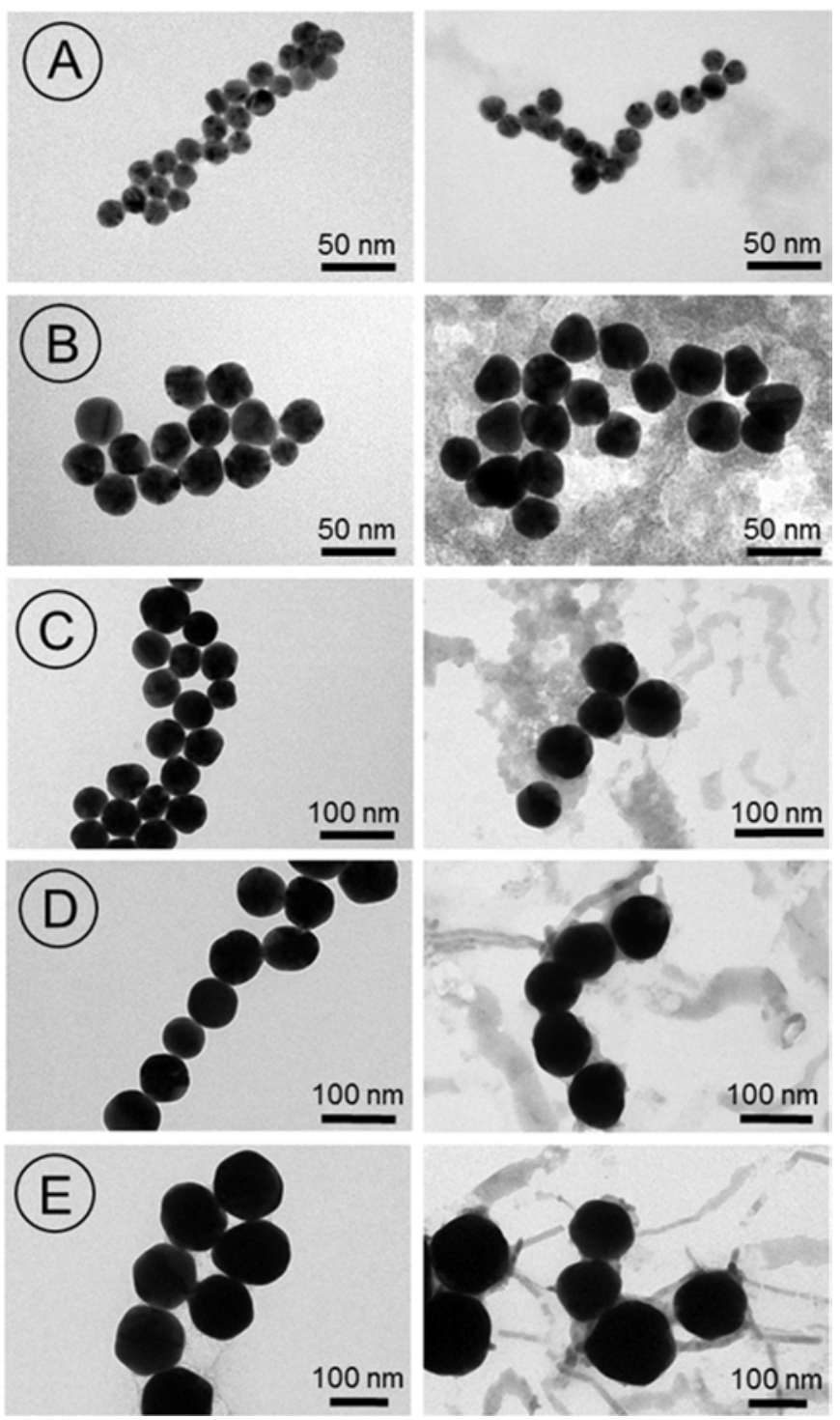

Fig. 1. Exemplary TEM images of AuNPs directly after synthesis (left) and after incubation in ASW with diatom cells (right). Different AuNP diameters are presented: $19 \mathrm{~nm}(\mathrm{~A}), 31 \mathrm{~nm}$ (B), $51 \mathrm{~nm}(\mathrm{C}), 75 \mathrm{~nm}(\mathrm{D})$, and $125 \mathrm{~nm}$ (E).

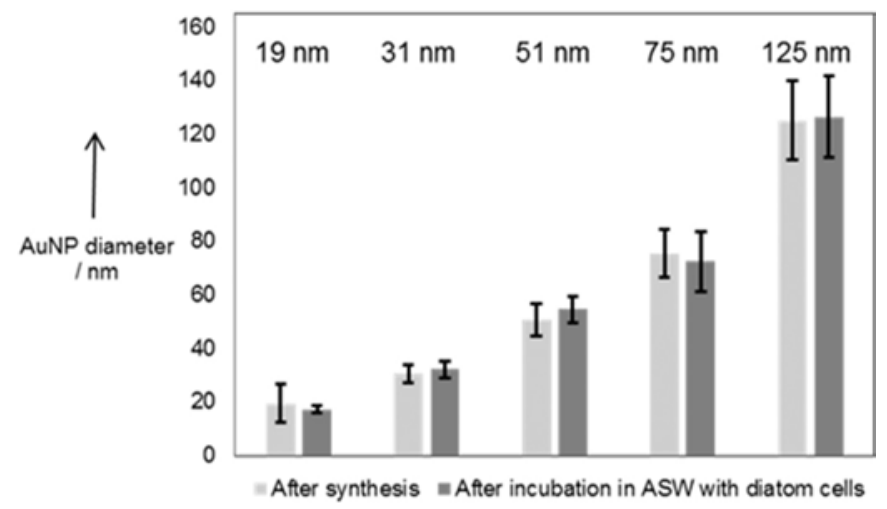

Fig. 2. Diameters of the AuNPs after synthesis and after incubation in ASW with diatom cells including standard deviation error bars. 


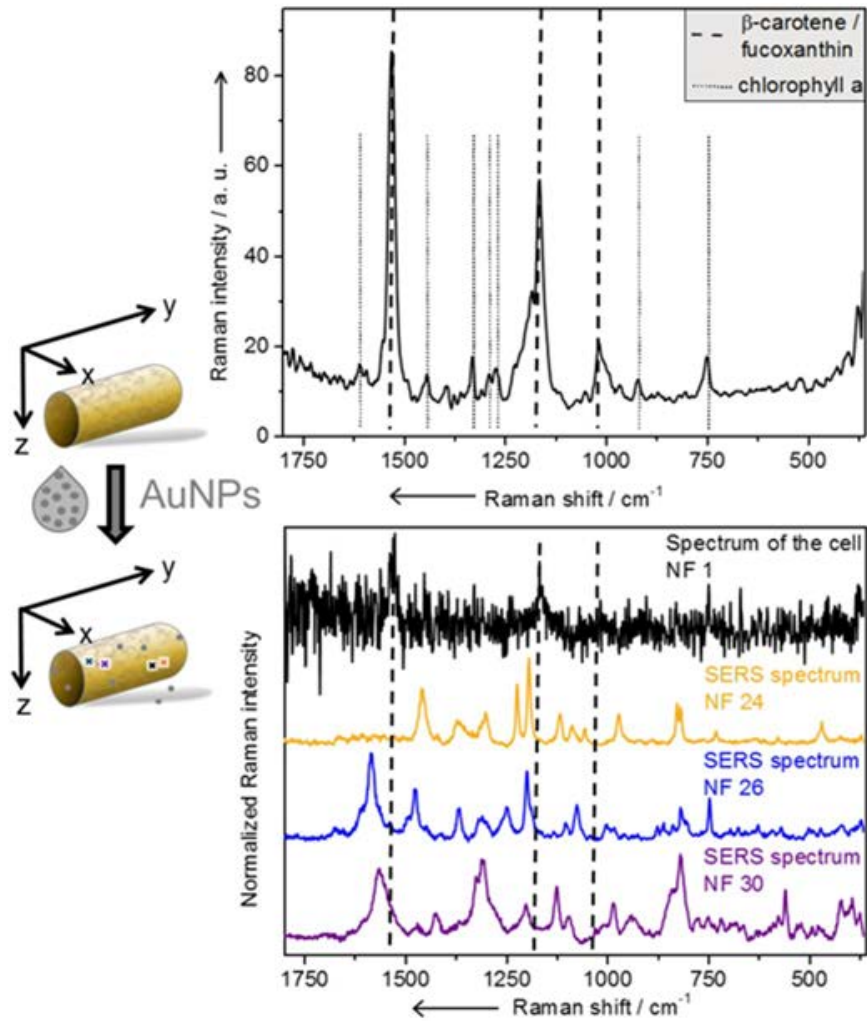

Fig. 3. Raman spectrum of bare $S$. turris cells (normal conditions: $95 \mathrm{~mW}, 5 \mathrm{~s}$ ) and spectral assignments (top). Normalized Raman spectrum (black) and exemplary SERS spectra (colored) of S. turris cells after incubation in $51 \mathrm{~nm}$ AuNP containing growth medium under soft $(8 \mathrm{~mW}, 109 \mathrm{~ms})$ measuring conditions (bottom). Normalization factors (NFs) illustrate the enhanced intensity of the SERS spectra. (For interpretation of the references to color in this figure legend, the reader is referred to the web version of this article.)

(using "soft" conditions of $8 \mathrm{~mW}$ laser power and $109 \mathrm{~ms}$ exposure time).

\subsubsection{Optimum AuNP concentration for incubation}

For SERS investigations, we first had to optimize the concentration of AuNPs added to the diatom cells. Three AuNP concentrations of $10^{-12} \mathrm{M}, 10^{-14} \mathrm{M}$ and $10^{-16} \mathrm{M}$ (determined according to the protocol of Haiss et al. [31]) have been tested. AuNPs were added to diatom cells in ASW and used in 2D Raman measurements. At least 10 cells were measured for each AuNP concentration and for the five different AuNP diameters of $19 \mathrm{~nm}, 31 \mathrm{~nm}, 51 \mathrm{~nm}, 75 \mathrm{~nm}$, and $125 \mathrm{~nm}$. The Raman images were scanned for the presence of at least one SERS spectrum and probabilities for finding SERS spectra in the diatom cultures were compared in Fig. 4. Regarding the tested concentrations, best results were observed for $10^{-12} \mathrm{M}$ AuNP. This concentration has, hence, been used for all of the following experiments.

It is known from literature [42] that in general only AuNPs $\geq 20 \mathrm{~nm}$ deliver significant enhancements taking in account the applied measuring conditions. This is in agreement with our results. However, we have observed the occurrence of SERS spectra to a minor degree as well at lower AuNP diameters (see Fig. 4). We assume that these SERS spectra generated by AuNPs of diameters below $20 \mathrm{~nm}$ either arise from a small percentage of AuNPs with strongly differing, larger diameter or from a low number of AuNP agglomerates. Interestingly, TEM images did not show extensive differences in agglomeration characteristics after AuNP synthesis in ultrapure water compared to AuNPs incubated in diatom cells containing ASW (see Fig. 1). We could neither observe an influence of AuNP size on the AuNP agglomeration behavior, nor an increased agglomeration behavior, which is sometimes described for

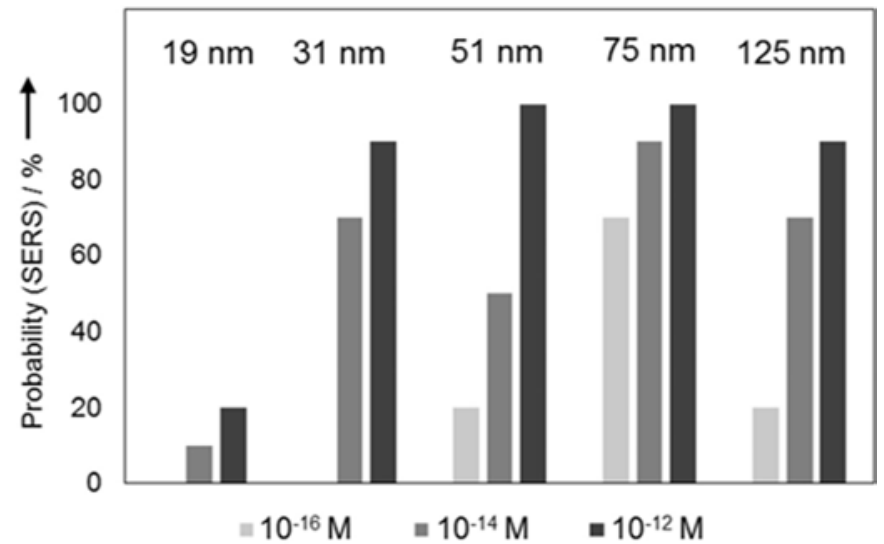

Fig. 4. Probability to find at least one SERS spectrum in each of the minimum 10 tested S. turris cells for 3 AuNP concentrations and 5 AuNP diameters.

AuNPs in salt water environments [43]. However, we suppose that few NPs actually form agglomerates and, thus, generate the small number of SERS spectra even for AuNPs of diameters below $20 \mathrm{~nm}$.

\subsubsection{Surface enhanced Raman spectroscopy}

Fig. 3 displays a pigment Raman spectrum under normal (top) and "soft" (bottom, black) measuring conditions and three exemplary SERS spectra (bottom, colored, "soft" measuring conditions) after cell incubation in $51 \mathrm{~nm}$ AuNP-containing ASW. New bands (see Fig. 3, blue, yellow, and purple spectra) are detected in addition to bands of the pigment spectrum (see Fig. 3, black). Such intense bands are only observable in the presence of AuNPs and must be caused by SERS [19]. Comparison of the normalization factors (NFs, see Fig. 3) confirms the enhanced band intensities of the SERS spectra compared to the nonenhanced pigment spectrum.

We have used these SERS spectra in 3D Raman imaging to in vivo determine the localization of the SERS generating AuNPs. For this purpose, living, individual cells after AuNP addition were analyzed by 3D Raman imaging. Results for $51 \mathrm{~nm}$ AuNPs are presented in Fig. 5, while 3D Raman images using the AuNPs with differing diameters are illustrated in the Supporting information (see Fig. S4). A microscopic image of such an investigated $S$. turris cell $(16 \times 67 \times 16 \mu \mathrm{m})$ is shown in Fig. 5a. The most intense pigment bands were used to localize the chloroplast and, by highlighting spectra with strong intensities of pigment bands in green, to represent the cell shape in a false color image (see Fig. 5b, c green). The $\mathrm{x} / \mathrm{y}$ cell dimensions in light microscopic images are in agreement with those of the resulting false color image, thus proving the applicability of the pigment band intensities to represent the cell shape. Many SERS spectra differing from the pigment spectrum were detected. The intracellular origin of the four selected spectra in Fig. 3 (bottom) is indicated in the microscopic and false color images of the investigated cell (colored crosses in Fig. 5a, c). Positions of a few more SERS spectra are illustrated in red (see Fig. 5b, c). This selection represents about $20 \%$ of all detected SERS spectra for this cell. SERS spectra which were preferentially detected close to the cell wall are not indicated in Fig. 5.

Fig. 5 demonstrates that SERS spectra are intracellular related to the $x$-y-dimensions of the cell. It can, however, not clearly be distinguished between SERS spectra close to the frustule or inside the cell for the $z$ dimension (see Fig. 5c). To determine the AuNP position in z-direction, Fig. 6 compares two sets of Raman (x/y-position 12/-5: black cross in Fig. 5) and SERS spectra (x/y-position 12/0: orange cross in Fig. 5$)$ over the full set of measured z-layers. The drop-like signal extending over several z-layers differing in signal intensity only is due to the microscope resolution, which in $\mathrm{z}$-direction is worse than in $\mathrm{x}$-y-direction.

The spectra measured at the position of the black cross in Fig. 6 (left) in the z-layers $0.5-18.5 \mu \mathrm{m}$ exhibit the typical cell spectrum 
a)
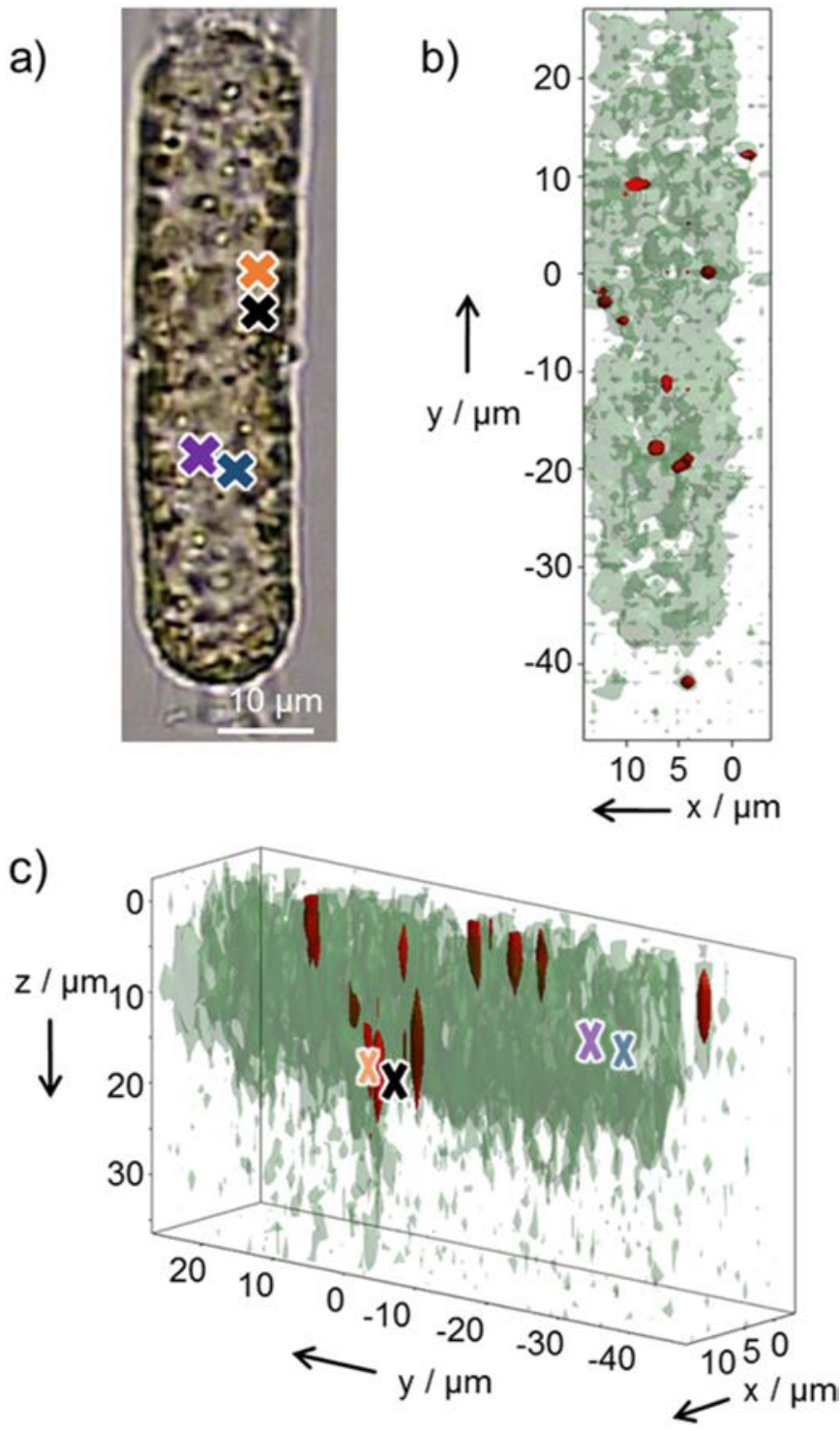

Fig. 5. Microscopic image of the measured S. turris cell (a) after incubation in cultivation medium containing $51 \mathrm{~nm}$ AuNPs. The false color image of the3D Raman image is presented in top (b) and in side view (c). Pixels containing the typical pigment spectrum are illustrated in green, pixels showing SERS spectra are marked in red. The differently colored crosses $(a, c)$ determine the localization of exemplary intracellular spectra, which are presented also in Fig. 3. (For interpretation of the references to color in this figure legend, the reader is referred to the web version of this article.)

dominated by the pigments. Z-layers between about 4 and $20 \mu \mathrm{m}$ (blue area, Fig. 6) show strong intensities of the pigment bands. These $z$ layers, thus, mark the cell dimension in z-direction, which is in agreement with the observed $16 \mu \mathrm{m}$ cell diameter of the light microscopic image (see Fig. 5a). The signal-to-noise ratio of the pigment spectra (Fig. 6, left) is low due to the "soft" measurement conditions. Above and below these z-layers, no signals are visible meaning that these spectra originate from outside the cell. In contrast, the spectra obtained at the orange cross (x/y-position 12/0 in Fig. 5) in the same z-layers offer a much higher signal-to-noise ratio characteristic for SERS spectra (see Fig. 6, right). The signal intensity shows a maximum at z-positions of 12.5 and $15.5 \mu \mathrm{m}$. The intensity decreases in both, positive and negative, z-directions. It is well known that the intensity of the SERS effect rapidly decreases with increasing distance $d$ from the NP surface (ISERS $\sim 1 / d^{12}$ ). This leads to enhanced signals only in close proximity (5$10 \mathrm{~nm}$ ) of the NPs [23]. The observed extension of SERS intensity in $\mathrm{z}$-direction must, thus, be due to the limited spatial resolution of the microscope in z-direction. Each spectrum contains contributions from regions above and below. Therefore, the AuNP generating the signal enhancement (see Fig. 6, right) has to be located in nm-proximity of the maximum spectral intensity, which is located between $z=12.5 \mu \mathrm{m}$ and $\mathrm{z}=15.5 \mu \mathrm{m}$. Comparison with the extension of the pigment spectrum representing the cell shape shows that this point of maximum intensity is clearly localized inside the diatom cell meaning that the SERS generating AuNP must be located intracellularly.

\subsubsection{Influence of the AuNP diameter}

The number of SERS spectra measured of cells incubated in ASW with AuNPs of different diameters showed that enlarging the AuNP diameter causes an increasing number of SERS spectra. Using $19 \mathrm{~nm}$ and $31 \mathrm{~nm}$ AuNPs, almost no SERS spectra are detectable $(19 \mathrm{~nm}$ : 0-1 spectra/image, $31 \mathrm{~nm}$ : 1-3 spectra/image). In contrast, larger AuNPs $\geq 51 \mathrm{~nm}$ generate at least 15 spectra per image. The augmented amount of gold (at an invariant number of NPs) coming along with the larger diameter apparently generates more SERS spectra around and inside the cells. This could explain the observed differences in toxicity (see Supporting information, Figs. S2 and S3) against different diameters of AuNPs. Using $125 \mathrm{~nm}$ AuNPs, many intracellular SERS spectra are detected. The intracellular AuNPs influence the diatom pigments which leads to the observed loss of fluorescence intensity (see above). Intracellular SERS spectra could be detected in all measured cells for AuNP diameters $\geq 51 \mathrm{~nm}$. However, no intracellular SERS spectra could be observed for smaller AuNPs. These AuNPs mainly generated SERS spectra close to the diatom cell walls. In general, AuNPs with diameters $\geq 20 \mathrm{~nm}$ constantly deliver SERS enhancements (see Fig. 4). However, all SERS spectra generated by $31 \mathrm{~nm}$ AuNPs as well as the sporadic SERS spectra generated by $19 \mathrm{~nm}$ AuNPs were localized outside the cell, often in close proximity to the cell walls - but never inside the cells.

This indicates a size-dependent AuNP uptake mechanism of diatoms (see Fig. 7). Smaller AuNPs are apparently prevented from cellular uptake whereas bigger AuNPs are incorporated into the cell. The uptake inhibition of smaller NPs could be explained by the thermodynamic model of a many-NPs-cell system for receptor-mediated endocytosis [44]. Following this model, the free energy gained by docking of single, small NPs $(\leq 40 \mathrm{~nm})$ to the receptor will not be sufficient to cover a subsequent wrapping by endocytic vesicles and the uptake of the NP into the cell. In contrast, AuNPs of 40-60 nm generate acceptable membrane bending rigidities of the endocytic vesicle and, thus, higher values of free energy when docking to the receptors [44].

To the best of our knowledge, this is the first in vivo detection of the intracellular presence of presynthesized NPs in living diatom cells. These AuNPs were added to the growth medium and must be taken up by the diatom cells. Our results are in agreement with the microscopic study of García et al. who have visualized NPs inside the diatom cell membrane using a cell cutting preparation of embedded, dead diatom cells [26].

\section{Conclusions}

In summary, we can state that AuNPs are taken up by the diatom $S$. turris. This uptake was monitored for the first time in vivo by 3D SERS on living cells. AuNPs with diameters $\geq 50 \mathrm{~nm}$ were clearly detectable inside the cell whereas smaller AuNPs were mainly located close to the cell wall. This indicates a size-dependent uptake mechanism that comes along with different toxicities. For more detailed information, this indication for a size-dependent uptake mechanism needs further analysis. Nevertheless, the in vivo detection of intracellular NPs constitutes the basis for the investigation of uptake and toxicity mechanisms and is, thus, fundamental for future environmental studies.

Supplementary data to this article can be found online at https:/ / doi.org/10.1016/j.algal.2019.101447. 


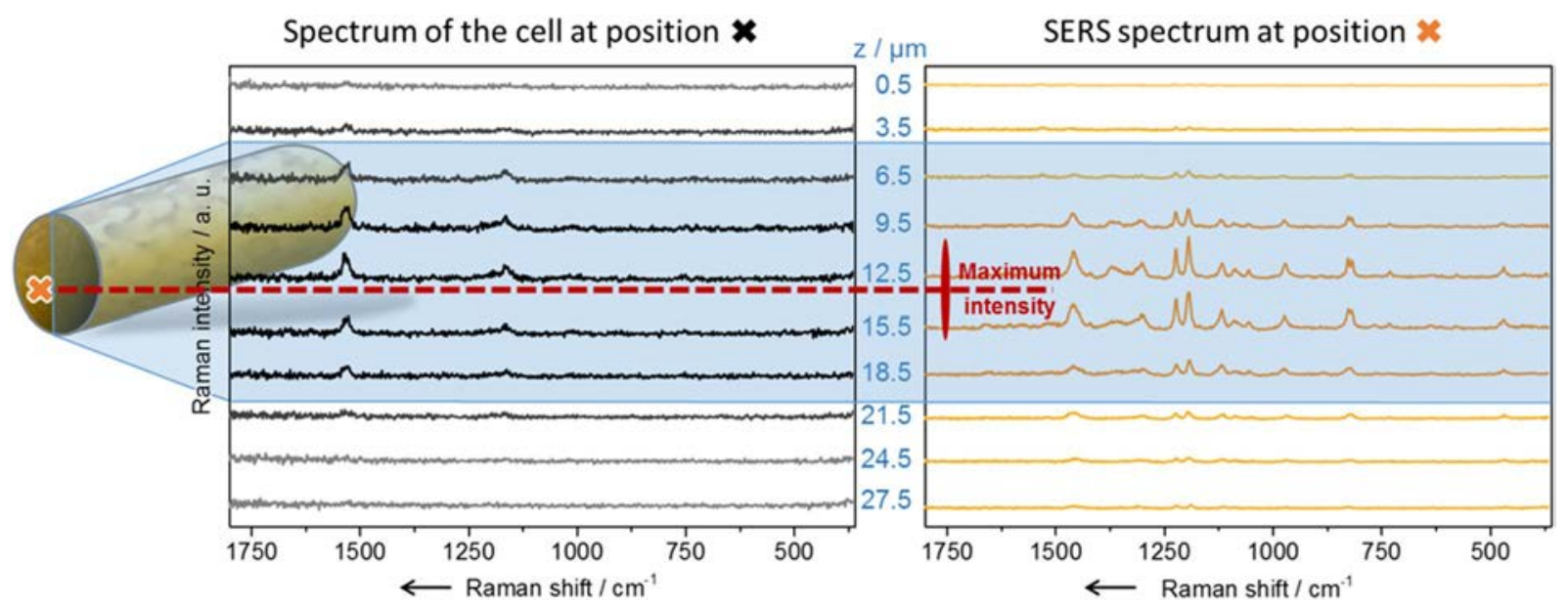

Fig. 6. Two sets of Raman spectra with respect to different z-layers. Raman spectra at the position of the black cross (see Fig. 5, $x / y=12 /-5$ ) show the pigment bands (left). The spectra at position of the orange cross (see Fig. $5, x / y=12 / 0$ ) represent an exemplary SERS spectrum. The spectra of strong intensity of pigment bands (left) represent the cell in z-dimension (marked in blue). The AuNP (orange cross) generating the SERS spectrum (right) is localized in the z-layer of maximum SERS intensity. (For interpretation of the references to color in this figure legend, the reader is referred to the web version of this article.)

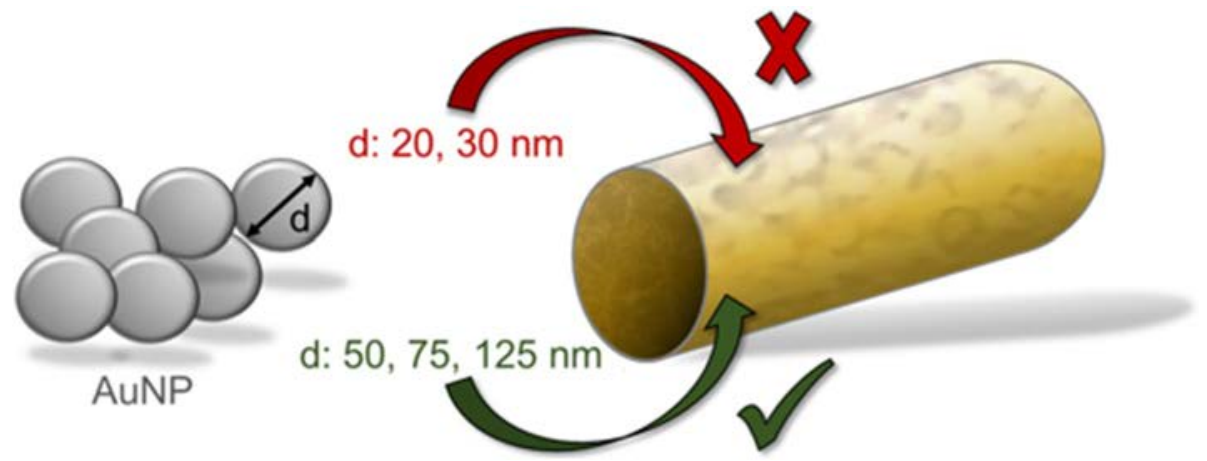

Fig. 7. Scheme indicating the size-dependent uptake of AuNPs into diatom cells.

\section{Acknowledgement}

The authors wish to thank M. Finger for developing and providing the Raman software.

Statement of informed consent, human/animal rights

No conflicts, informed consent, human or animal rights applicable.

Funding

Financial support by the Deutsche Forschungsgemeinschaft (grants no. BR1278/22-1 and BR1278/25-3) and AEROCAT ERC (grant no. 340419 ) is gratefully acknowledged.

Author contributions

N. Pytlik performed and evaluated the Raman and SERS experiments, the toxicity tests and cultivated the diatoms. B. Klemmed synthesized and characterized the AuNPs. S. Machill, A. Eychmüller, and E. Brunner supervised the scientific work. All authors wrote this manuscript together.

\section{Conflict of interest}

The authors wish to confirm that there are no known conflicts of interest associated with this publication.
References

[1] A. Eychmüller, Structure and photophysics of semiconductor nanocrystals, J. Phys. Chem. B 104 (2000) 6514-6528, https:// doi.org/10.1021/jp9943676.

[2] L.M. Liz-Marzán, Nanometals: formation and color, Mater. Today 7 (2004) 26-31, https:/ / doi.org/10.1016/S1369-7021(04)00080-X.

[3] S. Eustis, M.A. El-Sayed, Why gold nanoparticles are more precious than pretty gold: noble metal surface plasmon resonance and its enhancement of the radiative and nonradiative properties of nanocrystals of different shapes, Chem. Soc. Rev. 35 (2006) 209-217, https://doi.org/10.1039/b514191e.

[4] F. Piccinno, F. Gottschalk, S. Seeger, B. Nowack, Industrial production quantities and uses of ten engineered nanomaterials in Europe and the world, J. Nanopart. Res. 14 (2012) 1109, , https:// doi.org/10.1007/s11051-012-1109-9.

[5] E. Navarro, A. Baun, R. Behra, N.B. Hartmann, J. Filser, A.-J. Miao, A. Quigg, P.H. Santschi, L. Sigg, Environmental behavior and ecotoxicity of engineered nanoparticles to algae, plants, and fungi, Ecotoxicology 17 (2008) 372-386, https:/ / doi.org/10.1007/s10646-008-0214-0.

[6] D. Losic, J.G. Mitchell, N.H. Voelcker, Diatomaceous lessons in nanotechnology and advanced materials, Adv. Mater. 21 (2009) 2947-2958, https://doi.org/10.1002/ adma.200803778.

[7] R. Ragni, S.R. Cicco, D. Vona, G.M. Farinola, Multiple routes to smart nanostructured materials from diatom microalgae: a chemical perspective, Adv. Mater. 30 (2018) 1704289, https:// doi.org/10.1002/adma.201704289.

[8] C. Jeffryes, S.N. Agathos, G. Rorrer, Biogenic nanomaterials from photosynthetic microorganisms, Curr. Opin. Biotechnol. 33 (2015) 23-31, https://doi.org/10. 1016/j.copbio.2014.10.005.

[9] N.Pytlik, E. Brunner, Diatoms as potential "green" nanocomposite and nanoparticle synthesizers: challenges, prospects, and future materials applications, MRS Commun. 8 (2018) 322-331, https:/ / doi.org/10.1557/mrc.2018.34.

[10] E.V. Armbrust, J.A. Berges, C. Bowler, B.R. Green, D. Martinez, N.H. Putnam, S. Zhou, A.E. Allen, K.E. Apt, M. Bechner, M.A. Brzezinski, B.K. Chaal, A. Chiovitti, A.K. Davis, M.S. Demarest, J.C. Detter, T. Glavina, D. Goodstein, M.Z. Hadi, U. Hellsten, M. Hildebrand, B.D. Jenkins, J. Jurka, V.V. Kapitonov, N. Kröger, W.W.Y. Lau, T.W. Lane, F.W. Larimer, J.C. Lippmeier, S. Lucas, M. Medina, A. Montsant, M. Oborkin, M.S. Parker, B. Palenik, G.J. Pazour, P.M. Richardson, T.A. Rynearson, M.A. Saito, D.C. Schwartz, T. Kimberlee, V. Klaus, V. Assaf, 
F.P. Wilkerson, D.S. Rokhsar, The genome of the diatom Thalassiosira Pseudonana: ecology, evolution, and metabolism, Science 306 (2004) 79-86, https:// doi.org/10. 1126/science. 1101156

[11] K.G.V. Bondoc, J. Heuschele, J. Gillard, W. Vyverman, G. Pohnert, Selective silicatedirected motility in diatoms, Nat. Commun. 7 (2016) 10540, , https:/ / doi.org/10. 1038/ncomms10540.

[12] J.Parkinson, R. Gordon, Beyond micromachining: the potential of diatoms, Trends Biotechnol. 17 (1999) 190-196.

[13] N. Kröger, N. Poulsen, Diatoms - from cell wall biogenesis to nanotechnology, Annu. Rev. Genet. 42 (2008) 83-107, https://doi.org/10.1146/annurev.genet.41. 110306.130109.

[14] C. Jeffryes, J. Campbell, H. Li, J. Jiao, G. Rorrer, The potential of diatom nanobiotechnology for applications in solar cells, batteries, and electroluminescent devices, Energy Environ. Sci. 4 (2011) 3930-3941, https://doi.org/10.1039/ c0ee00306a.

[15] A.Schröfel,G.Kratošová, M. Bohunická, E. Dobročka, I. Vávra, Biosynthesis of gold nanoparticles using diatoms-silica-gold and EPS-gold bionanocomposite formation, J. Nanopart. Res. 13 (2011) 3207-3216, https://doi.org/10.1007/s11051-0110221-6.

[16] P. Roychoudhury, C. Nandi, R. Pal, Diatom-based biosynthesis of gold-silica nanocomposite and their DNA binding affinity, J. Appl. Phycol. 28 (2016) 2857-2863, https://doi.org/10.1007/s10811-016-0809-4.

[17] J. Jena, N. Pradhan, B.P. Dash, P.K. Panda, B.K. Mishra, Pigment mediated biogenic synthesis of silver nanoparticles using diatom Amphora sp. and its antimicrobia activity, J. Saudi Chem. Soc. 19 (2015) 661-666, https:// doi.org/10.1016/j.jscs. 2014.06.005.

[18] H.P. Borase, C.D. Patil, R.K. Suryawanshi, S.H. Koli, B.V. Mohite, G. Benelli, S.V. Patil, Mechanistic approach for fabrication of gold nanoparticles by Nitzschi diatom and their antibacterial activity, Bioprocess Biosyst. Eng. 40 (2017) 14371446, https://doi.org/10.1007/s00449-017-1801-3.

[19] N. Pytlik, J. Kaden, M. Finger, J. Naumann, S. Wanke, S. Machill, E. Brunner, Biological synthesis of gold nanoparticles by the diatom Stephanopyxis turris and in vivo SERS analyses, Algal Res. 28 (2017) 9-15, https:/ / doi.org/10.1016/j.algal. 2017.10.004.

[20] A. Feurtet-Mazel, S. Mornet, L. Charron, N. Mesmer-Dudons, R. Maury-Brachet, M. Baudrimont, Biosynthesis of gold nanoparticles by the living freshwater diatom Eolimna minima, a species developed in river biofilms, Environ. Sci. Pollut. Res. 23 (2016) 4334-4339, https:/ / doi.org/10.1007/s11356-015-4139-x.

[21] S.K. Das, E. Marsili, A green chemical approach for the synthesis of gold nanoparticles: characterization and mechanistic aspect, Rev. Environ. Sci. Biotechnol. 9 (2010) 199-204, https:/ / doi.org/10.1007/s11157-010-9188-5.

[22] R.H. Lahr, P.J. Vikesland, Surface-enhanced Raman spectroscopy (SERS) cellular imaging of intracellulary biosynthesized gold nanoparticles, ACS Sustain. Chem. Eng. 2 (2014) 1599-1608.

[23] M. Procházka, Surface- Enhanced Raman Spectroscopy - Bioanalytical Biomolecular and Medical Applications, Springer, Cham, 2016.

[24] X. Peng, S. Palma, N.S. Fisher, S.S. Wong, Effect of morphology of ZnO nanostructures on their toxicity to marine algae, Aquat. Toxicol. 102 (2011) 186-196, https://doi.org/10.1016/j.aquatox.2011.01.014

[25] G.K. Bielmyer-Fraser, T.A. Jarvis, H.S. Lenihan, R.J. Miller, Cellular partitioning of nanoparticulate versus dissolved metals in marine phytoplankton, Environ. Sci. Technol. 48 (2014) 13443-13450, https:/ / doi.org/10.1021/es501187g.

[26] C.P. García, A.D. Burchardt, R.N. Carvalho, D. Gilliland, D.C. António, F. Rossi, T. Lettieri, Detection of silver nanoparticles inside marine diatom Thalassiosira pseudonana by electron microscopy and focused ion beam, PLoS One 9 (2014) 1-7, https://doi.org/10.1371/journal.pone.0096078

[27] G. Pletikapić, V. Žutić, I.V. Vrček, V. Svetličić, Atomic force microscopy characterization of silver nanoparticles interactions with marine diatom cells and extracellular polymeric substance, J. Mol. Recognit. 25 (2012) 309-317, https:/ / doi. org/10.1002/jmr.2177.

[28] P. Harrison, R.E. Waters, F.J.R. Taylor, A broad spectrum artificial sea water medium for coastal and open ocean phytoplankton, J. Phycol. 16 (1980) 28-35.

[29] G. Frens, Controlled nucleation for the regulation of the particle size in monodisperse gold suspensions, Nat. Phys. Sci. 241 (1973) 20-22, https://doi.org/10. 1038/physci241020a0.

[30] C. Ziegler, A. Eychmüller, Seeded growth synthesis of uniform gold nanoparticles with diameters of 15-300 nm, J. Phys. Chem. C 115 (2011) 4502-4506, https:/ / doi org/10.1021/jp1106982.

[31] W. Haiss, N.T.K. Thanh, J. Aveyard, D.G. Fernig, Determination of Size and Concentration of Gold Nanoparticles From UV - Vis Spectra, 79 (2015), pp 4215-4221, https://doi.org/10.1021/ac0702084.

[32] G. Sitterley, Poly-lysine, BioFiles 8 (2008) 12

[33] M. Finger, Analyse der Verteilung von Inhaltsstoffen im Papierquerschnitt mittels Raman-Chemical-Imaging, TU Dresden, 2017.

[34] A. Jantschke, C. Fischer, R. Hensel, H.-G. Braun, E. Brunner, Directed assembly of nanoparticles to isolated diatom valves using the non-wetting characteristics after pyrolysis, Nanoscale 6 (2014) 11637-11645, https:/ / doi.org/10.1039/c4nr02662d.

[35] B. Tesson, M. Hildebrand, Characterization and localization of insoluble organic matrices associated with diatom cell walls: insight into their roles during cell wall formation, PLoS One 8 (2013), https:/ / doi.org/10.1371/journal.pone.0061675.

[36] D. Losic, Diatom Nanotechnology - Progress and Emerging Applications, The Royal Society of Chemistry, Croydon, 2018.

[37] A. Jantschke, E. Koers, D. Mance, M. Weingarth, E. Brunner, M. Baldus, Insight into the supramolecular architecture of intact diatom biosilica from DNP-supported solid-state NMR spectroscopy, Angew. Chem. Int. Ed. 54 (2015) 15069-15073, https://doi.org/10.1002/anie.201507327.

[38] J. Morrissey, C. Bowler, Iron utilization in marine cyanobacteria and eukaryotic algae, Front. Microbiol. 3 (2012) 1-13, https:/ / doi.org/10.3389/fmicb.2012. 00043.

[39] E. Kazamia, R. Sutak, J. Paz-Yepes, R.G. Dorrell, F.R.J. Vieira, J. Mach, J. Morrissey, S. Leon, F. Lam, E. Pelletier, J.M. Camadro, C. Bowler, E. Lesuisse, Endocytosismediated siderophore uptake as a strategy for Fe acquisition in diatoms, Sci. Adv. 4 (2018) eaar4536, https://doi.org/10.1126/sciadv.aar4536.

[40] B. Xia, B. Chen, X. Sun, K. Qu, F. Ma, M. Du, Interaction of $\mathrm{TiO}_{2}$ nanoparticles with the marine microalga Nitzschia closterium: growth inhibition, oxidative stress and internalization, Sci. Total Environ. 508 (2015) 525-533, https://doi.org/10.1016/j. scitotenv.2014.11.066.

[41] L. Clément, C. Hurel, N. Marmier, Toxixity of $\mathrm{TiO}_{2}$ nanoparticles to cladocerans, algae, rotifers and plants - effects of size and crystalline structure, Chemosphere 90 (2013) 1083-1090.

[42] A. Shamsaie, J. Heim, A.A. Yanik, J. Irudayaraj, Intracellular quantification by surface enhanced Raman spectroscopy, Chem. Phys. Lett. 461 (2008) 131-135, https:/ / doi.org/10.1016/j.cplett.2008.06.064.

[43] S. Deol, N. Weerasuriya, Y.-S. Shon, Stability, cytotoxicity and cell uptake of watersoluble dendron-conjugated gold nanoparticles with 3, 12 and $17 \mathrm{~nm}$ cores, J. Mater. Chem. B 3 (2015) 6071-6080, https://doi.org/10.1039/C5TB00608B.

[44] S.H. Wang, C.-W. Lee, A. Chiou, P.-K. Wei, Size-dependent endocytosis of gold nanoparticles studied by three-dimensional mapping of plasmonic scattering images, J. Nanobiotechnol. 8 (2010) 1-13, https:/ / doi.org/10.1186/1477-3155$8-33$. 